\title{
Screening paper currency for Mycobacterium tuberculosis using loop-mediated isothermal amplification
}

\author{
Manoj Nimesh, Rigzin Kang, Deepali Joon* \\ Department of Zoology, Sri Guru Tegh Bahadur Khalsa College, North Campus, University of Delhi, New Delhi, India.
}

\begin{tabular}{l}
\hline ARTICLE INFO \\
\hline Article history: \\
Received: September 01, 2021 \\
Accepted: November 17, 2021 \\
Available Online: January 07, 2022
\end{tabular}

Key words:

Mycobacterium tuberculosis,

loop-mediated isothermal

amplification (LAMP) technique,

paper currency, tuberculosis

\begin{abstract}
Paper currency notes are the most commonly exchanged fomites which can be contaminated and have the potential to transmit pathogenic organisms. The presence of tuberculosis causative bacteria on the most commonly circulated Indian currency notes was investigated using loop-mediated isothermal amplification (LAMP). Out of 1,000 random samples of 10-rupee Indian currency notes, $11.3 \%$ tested positive for the presence of genomic DNA of Mycobacterium tuberculosis. It was observed that soiled/old notes are more likely than new currency notes to harbor M. tuberculosis. This study demonstrates the novel application of LAMP technique for screening fomites for the presence of pathogens.
\end{abstract}

\section{INTRODUCTION}

Fomites have been known to transmit many deadly diseases [1]. The COVID-19 pandemic has highlighted the importance of exploring the surface transmission possibility of respiratory diseases [2]. Tuberculosis (TB) has remained a deadly disease worldwide for centuries. It is known that the disease is spread by direct contact via droplet nuclei infection [3]. However, there is a possibility of other routes of infection because the TB-causing pathogen is known to remain viable for several days and months in the environment $[4,5]$. Paper currency notes may be one such potential fomite because they frequently exchange hands. In countries such as India, the hygienic practices while handling money are not followed by the majority of the population. The rough surface of paper currency can serve as an excellent environment for microbes, including bacteria, fungi, and viruses [6,7]. There are several studies that have investigated and confirmed the presence of various diseasecausing pathogens on currency notes across all nations [6,8-13].

*Corresponding Author

Deepali Joon, Department of Zoology, Sri Guru Tegh Bahadur Khalsa College, North Campus, University of Delhi, New Delhi, India. E-mail: deepalijoon@gmail.com
The most commonly described pathogenic bacterial genera are Escherichia (E. coli), Klebsiella, Staphylococcus, Enterococcus, Salmonella, Shigella, Pseudomonas, and Proteus [7,14-16]. In recent literature, several studies have also explored the potential of antibiotic-resistant strains transmission via the currency notes $[7,10,13,14,16-20]$. Most of these studies have reported the presence of pathogens-causing foodborne illnesses. There is very scarce literature reporting the presence of Mycobacterium on currency notes [16]. Hence, the aim of this study was to investigate the contamination of Indian paper currency notes with Mycobacterium tuberculosis using the novel technique of loopmediated isothermal amplification (LAMP).

\section{MATERIAL AND METHODS}

For this cross-sectional study, samples were selected for the most circulated notes by the Reserve Bank of India of small denomination ₹10. One thousand paper currency samples were collected in sterile plastic bags from random spots such as street vendors, grocery shops, canteens, tea shops, chemists, etc., across the Delhi metropolitan city (National Capital Territory of Delhi). The currency notes were also collected from people in the vicinity of Vallabhbhai Patel Chest Institute, University of Delhi. These included the visiting patients, their family members, food stalls 
owners, vendors, and rickshaw pullers. The currency notes were collected in sterile plastic bags and brought to the laboratory in the institution. All the individuals were given new notes from the bank as equivalent replacement. The currency notes were classified according to condition, appearance, and degree of dirtiness as new, moderate, and soiled/torn (Set A, B, and C, respectively). Out of 1,000, 175, 293, and 532 notes were categorized into Set A, $\mathrm{B}$, and $\mathrm{C}$, respectively.

For total genomic DNA isolation, each currency note was gently washed with Tween- 80 solution $(0.05 \%)$. This collected solution was centrifuged at $10,000 \mathrm{rpm}$ for 10 minutes to obtain a pellet. Chelex-100 solution containing 10\% Chelex-100 resin, $0.03 \%$ Triton X-100, and $0.3 \%$ Tween 20 was added to the pellet [21]. It was mixed and incubated in a dry bath at $90^{\circ} \mathrm{C}$ for 30 minutes. Then, it was allowed to cool down to room temperature and centrifuged at 10,000 rpm for 5 minutes. The supernatant was carefully transferred to a fresh tube and stored in a deep freezer for further use. Five microliters of the supernatant was used as template for LAMP reaction to specifically amplify target gene of M. tuberculosis. The primers were used to amplify $190 \mathrm{bp}$ region of $s d a A$ gene of $M$. tuberculosis according to the LAMP reaction mixture described by Nimesh et al. [22-24]. The primer sequences (Patent Number 362827) and the target region are shown in the Table 1 and Figure 1. The specificity of these primers has been tested with various reference species/strains of mycobacteria $[23,24]$. Genomic DNA of M. tuberculosis was used as positive control and no template control were included with each set of specimens for amplification.
The genomic DNA isolated from the specimens was used as template in the total volume of $25 \mu \mathrm{l}$ of reaction mixture containing $20 \mathrm{mM}$ Tris- $\mathrm{HCl}(\mathrm{pH} 8.8), 50 \mathrm{mM} \mathrm{KCl}, 10 \mathrm{mM}\left(\mathrm{NH}_{4}\right)_{2} \mathrm{SO}_{4}$, $0.1 \%$ Tween-20, $8 \mathrm{mM} \mathrm{MgSO}_{4}, 0.8 \mathrm{M}$ betaine, $1.0 \mathrm{mM}$ each deoxynucleotide triphosphates (deoxyadenosine triphosphate, deoxyguanosine triphosphate, deoxycytidine triphosphate, deoxyuridine triphosphate), $0.2 \mu \mathrm{M}$ each of F3 and B3 primers, 0.8 $\mu \mathrm{M}$ each of forward Inner Primer (FIP) and backward Inner Primer (BIP), and 8 U Bst 2.0 DNA polymerase (New England Biolabs, USA). The reaction mixture was incubated at $37^{\circ} \mathrm{C}$ for 10 minutes with $3 \mathrm{U}$ Uracil-DNA Glycosylase enzyme followed by $65^{\circ} \mathrm{C}$ for 45 minutes and inactivated at $80^{\circ} \mathrm{C}$ for 5 minutes [23]. For results, the amplified products were observed with the naked eye by adding 2 $\mu \mathrm{l}$ of $1,000 \times$ SYBR Green I to the tube and noticing the color of the solution. The binding of SYBR green to amplified DNA changed the color of solution to green while the tubes with no amplification remained orange (Fig. 2). To confirm the specificity of the LAMP assay in positive specimens, amplified products from the same were checked by agarose gel electrophoresis after restriction digestion with SacII restriction enzyme at $37^{\circ} \mathrm{C}$ for 4 hours (Fig. 3). Furthermore, the positive specimens were also verified by DNA sequencing for the target region of amplified $s d a A$ gene using outer primers.

\section{RESULT AND DISCUSSION}

The positive specimens showed color change from orange to green upon addition of SYBR Green I dye, as shown in Figure 2. The positive percentage was determined to be $11.3 \%$ (113 out of

Table 1: Sequence of LAMP primers used for specific amplification of the $s d a A$ gene ${ }^{\text {a }}$ of $M$. tuberculosis.

\begin{tabular}{|c|c|c|c|}
\hline Primer $^{\mathrm{b}}$ & Type & Length & Sequence \\
\hline F3 & Forward outer & 20-mer & 5'- TAGGGAAGGGCAACTGAGCA -3' \\
\hline B3 & Backward outer & 20-mer & 5'- AGCGTGATATCGACCTGCAT -3' \\
\hline FIP & Forward inner $(\mathrm{F} 1 \mathrm{C}+\mathrm{TTTT}+\mathrm{F} 2)$ & $\begin{array}{l}\text { 40-mer (F1C:18- } \\
\text { mer, F2:18-mer) }\end{array}$ & $\begin{array}{l}\text { 5'-CACGGAACAGACCAGCGGTTTT } \\
\text { GGATGTTGGCCGCTGTTG-3' }\end{array}$ \\
\hline BIP & Backward inner (B1C + TTTT + B2) & $\begin{array}{l}\text { 38-mer (B1C:17- } \\
\text { mer, B2:17-mer) }\end{array}$ & $\begin{array}{l}\text { 5'-CCGCGGCAGTGAACGTCTTTT } \\
\text { GCCAACGCATCCCAACG-3' }\end{array}$ \\
\hline
\end{tabular}

${ }^{a}$ GenBank accession no.: CP072765.1.

${ }^{\mathrm{b}}$ For nomenclature, see reference [25].

\section{F3 $\quad F 2 \quad F 1$}

5'-TAGGGAAGGGCAACTGAGCATGGATGTTGGCCGCTGTTGCCGCTGGTCTGTTCCGTGACGATGAACCCTCCGCCCACCGAAAAATAAGTCTCGGTGGC 3'-ATCCCTTCCCGTTGACTCGTACCTACAACCGGCGACAACGGCGACCAGACAAGGCACTGCTACTTGGGAGGCGGGTGGCTTTTTATTCAGAGCCACCG

F3c $\quad$ F2c $\quad$ F1c

B1C B2C B3C

CAAGACGCGGCCGTGTGGGCCCGCGGCAGTGAACGTCATTCCGTTGGGATGCGTTGGCAGAACGATGTCGGGATGCAGGTCGATATCACGCT-3' GTTCTGCGCCGGCACACCCGGGCGCCGTCACTTGCAGTAAGGCAACCCTACGCAACCGTCTTGCTACAGCCCTACGTCCAGCTATAGTGCGA- 5'

\section{B1 B2 B3}

Figure 1: Schematic representation of primer sequences in the $190 \mathrm{bp}$ region of sdaA gene of M. tuberculosis (Refer to Table 1 for details). 

amplification 2022;10(01):221-225

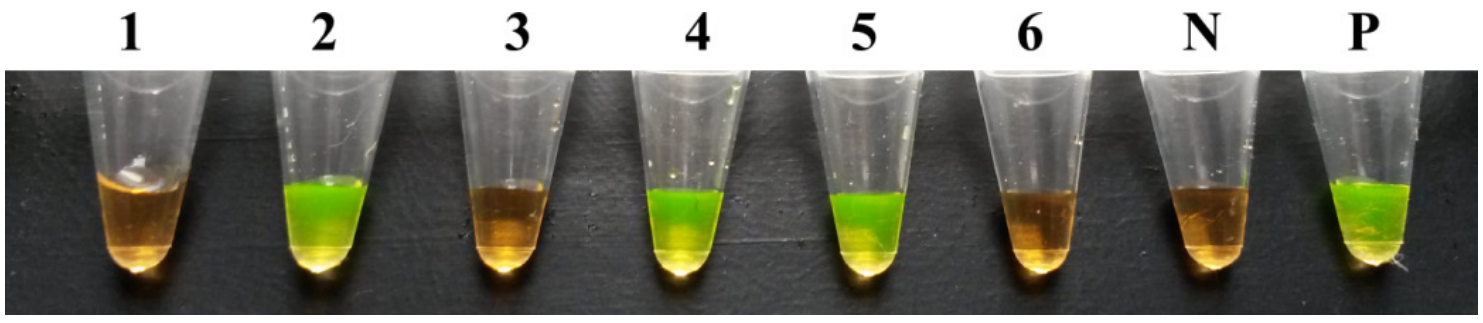

Figure 2: Visual results for LAMP for six specimens (tube 1-6) with negative $(\mathrm{N})$ and positive $(\mathrm{P})$ controls, respectively. The fluorescent green color depicts the presence of amplified product.
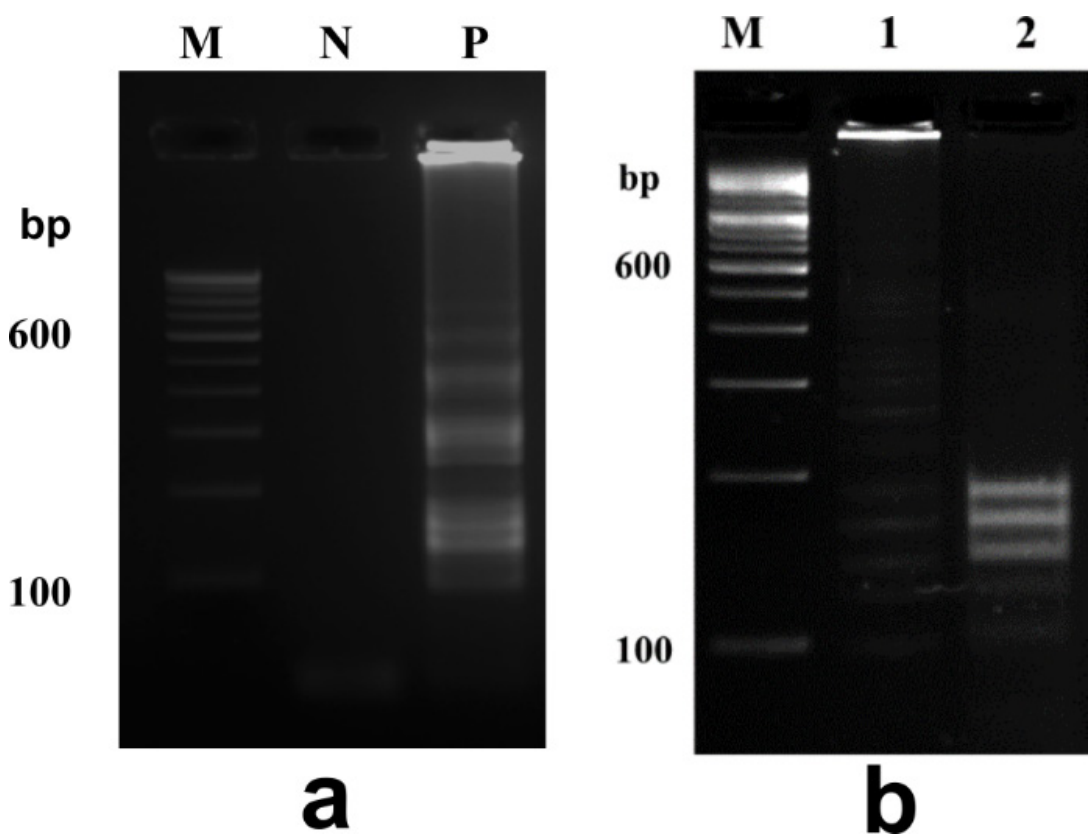

Figure 3: Agarose gel electrophoresis results for $s d a A$ LAMP reaction products. a) Amplified product and b) analysis with SacII restriction enzyme. Lane M shows the 100 bp DNA ladder; lane $\mathrm{N}$ shows no template control; and lane $\mathrm{P}$ shows positive control (5 $\mu$ l of amplification products) ; lane 1 shows $2 \mu 1$ of amplification products before digestion and lane 2 shows amplified reaction products after restriction digestion with SacII, confirming the specificity of amplified products.

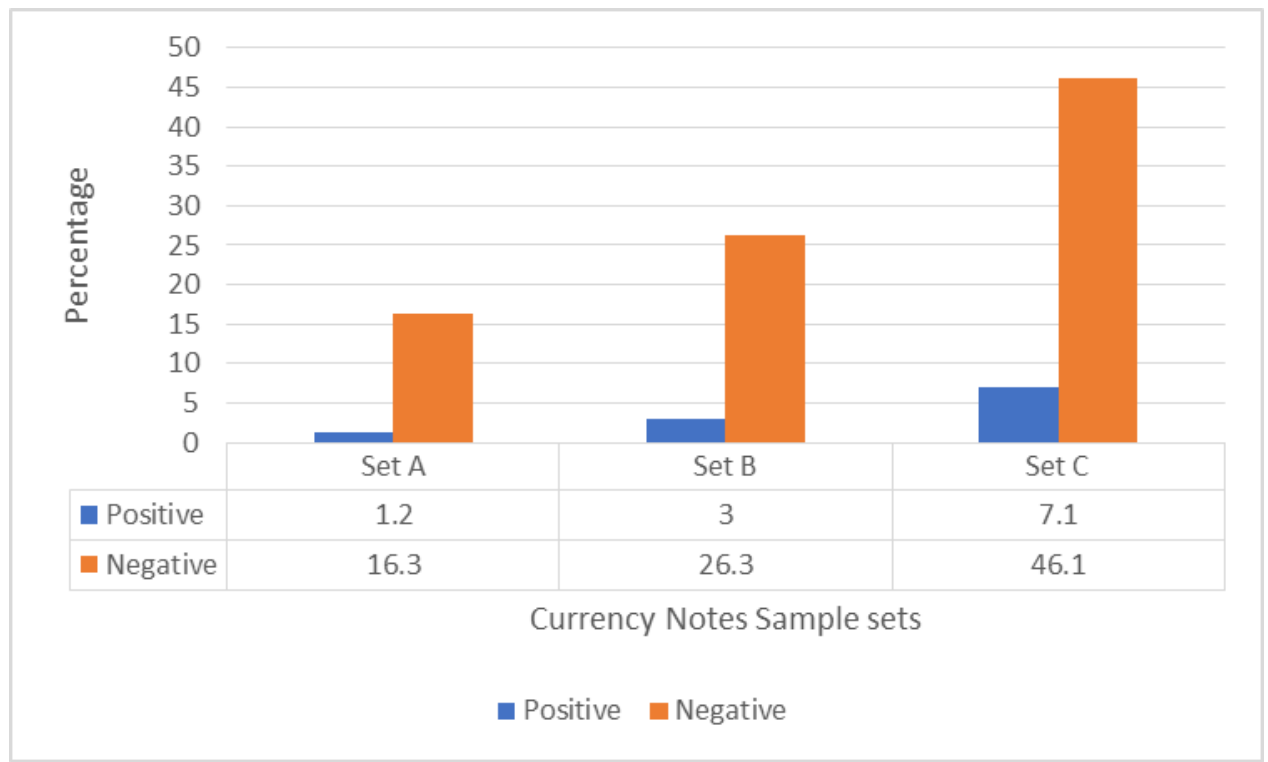

Figure 4: Bar chart depicting the percentage in different categories of currency note samples. (Set A, B, and C refers to new, moderate, and soiled/torn currency notes, respectively). 
1,000) for the presence of $M$. tuberculosis. The category-wise positive percentage is shown in Figure 4. A chi-square test of independence was carried out to examine the relationship between dirtiness or new versus soiled currency notes and the presence of $M$. tuberculosis. The relationship between these variables was significant, $X^{2}(2, N=1,000)=5.99, p$ value $=0.04986$ (The result is significant at $p<0.05)$ using Statistical Package for the Social Sciences software (version 26.0). The $p$-value indicates that these variables are not independent of each other.

This is a novel study to report the presence of M. tuberculosis on paper currency notes using LAMP, to the best of our knowledge. Culture method is the gold standard method for confirmation of viable pathogens, but it is very time-consuming for slow-growing microbes such as $M$. tuberculosis and it requires well-contained biosafety facilities [26]. Recent studies have highlighted the importance of using the cultivation independent methods for detecting mycobacteria on fomites when possible due to low sensitivity of culture [27]. Sequencing and polymerase Chain Reaction (PCR) are also commonly used techniques but these methods require sophisticated instruments and expensive reagents. LAMP is based on isothermal amplification using six distinct regions targeted by primers [25]. This method does not require a thermal cycler and is more sensitive and specific than PCR. This technique is less prone to presence of inhibitors in specimens [28,29]. Even since its inception, this technique has been widely applied in detection of various disease-causing pathogens including bacteria, virus, fungi, parasites, etc. It has also been used for many other applications such as cancer diagnosis, detection of environmental contaminants and food adulterants, allergens, and DNA profiling studies [29-31]. Owing to its superior qualities and efficiency, the LAMP technique was considered for screening currency notes for presence of $M$. tuberculosis.

According to our findings, $11.3 \%$ of the currency notes included in the study showed the presence of genomic DNA of $M$. tuberculosis. It has been reported that microbial contamination of currency notes can be up to $100 \%$ [17]. However, no such data is available for $M$. tuberculosis. The statistical analysis showed that soiled/old notes are more likely than new currency notes to show the presence of $M$. tuberculosis. This can be explained by the less favorable environment provided by a clean smooth surface and probable less frequent exchange of new notes in the population.

Large sample size and highly sensitive detection techniques are the strengths of this study. The caveats include inability to differentiate between viable and dead microbes and the sampling is limited to small denomination currency notes only. This study paves way for further inquiry into viability of $M$. tuberculosis pathogens on the currency note surface and highlights the need for exploring the possibility of transmission [4,5]. It has been reported that $M$. tuberculosis can persist on dry and inanimate surfaces for several weeks [32]. However, there are knowledge gaps in transmission dynamics of TB disease by fomites [4].

\section{CONCLUSION}

Contaminated currency might pose a public health problem in the global control of TB and there is also need to investigate the presence of drug-resistant pathogens. The present findings are an important first step toward the possibility of risk of transmission of TB by fomites, which warrants further investigation using approaches that can confirm the duration of persistence, viability, bacterial load, and chances of re-aerosolization. This study has implications for TB research, public health, and application of LAMP for pathogen screening on surfaces as well as bio-surveillance.

\section{REFERENCES}

[1] Stephens B, Azimi P, Thoemmes MS, Heidarinejad M, Allen JG, Gilbert JA. Microbial exchange via fomites and implications for human health. Curr Pollut Rep 2019;5(4):198-213.

[2] Castaño N, Cordts SC, Kurosu Jalil M, Zhang KS, Koppaka S, Bick $\mathrm{AD}$, et al. Fomite transmission, physicochemical origin of virussurface interactions, and disinfection strategies for enveloped viruses with applications to SARS-CoV-2. ACS Omega 2021;6(10):6509-27.

[3] Nardell EA. Transmission and institutional infection control of tuberculosis. Cold Spring Harb Perspect Med 2016; doi:10.1101/ cshperspect.a018192

[4] Martinez L, Verma R, Croda J, Horsburgh CR, Walter KS, Degner N, et al. Detection, survival and infectious potential of Mycobacterium tuberculosis in the environment: a review of the evidence and epidemiological implications. Eur Respir J. 2019;53(6):1802302.

[5] Kramer A, Schwebke I, Kampf G. How long do nosocomial pathogens persist on inanimate surfaces? A systematic review. BMC Infect Dis 2006;6; doi:10.1186/1471-2334-6-130

[6] Angelakis E, Azhar EI, Bibi F, Yasir M, Al-Ghamdi AK, Ashshi AM, et al. Paper money and coins as potential vectors of transmissible disease. Fut Microbiol 2014;9(2):249-61.

[7] Demirci M, Celepler Y, Dincer Ş, Yildirim Í, Çiğrikci HN, Kalyenci $\mathrm{N}$, et al. Should we leave the paper currency? A microbiological examination. Rev Esp Quimioter 2020;33(2):94-102.

[8] da Fonseca TAP, Pessôa R, Sanabani SS. Molecular analysis of bacterial microbiota on Brazilian currency note surfaces. Int J Environ Res Public Health 2015;12(10):13276-88.

[9] Hajipour N, Moosavy MH, Rostamzadeh B, Hajibemani A. Contamination of coins and banknotes as sources of transmission of parasitic pathogens: a pilot study from Iran. Public Health 2020;186:116-8.

[10] Heshiki Y, Dissanayake T, Zheng T, Kang K, Yueqiong N, Xu $\mathrm{Z}$, et al. Toward a metagenomic understanding on the bacterial composition and resistome in Hong Kong banknotes. Front Microbiol 2017;8(APR):632.

[11] Kumar JD, Negi YK, Gaur A, Khanna D. Detection of virulence genes in Staphylococcus aureus isolated from paper currency. Int J Infect Dis 2009;13(6):e450-5; doi: 10.1016/j.ijid.2009.02.020

[12] Maritz JM, Sullivan SA, Prill RJ, Aksoy E, Scheid P, Carlton JM, et al. Filthy lucre: a metagenomic pilot study of microbes found on circulating currency in New York City. PLoS One 2017;12(4):e0175527.

[13] Akoachere JFTK, Gaelle N, Dilonga HM, Nkuo-Akenji TK. Public health implications of contamination of Franc CFA (XAF) circulating in Buea (Cameroon) with drug resistant pathogens. BMC Res Notes 2014;7(1); doi:10.1186/1756-0500-7-16

[14] Yar DD. Bacterial contaminants and antibiogram of ghana paper currency notes in circulation and their associated health risks in Asante-Mampong, Ghana. Int J Microbiol 2020;2020:Article ID 8833757.

[15] Ofoedu CE, Iwouno JO, Agunwah IM, Obodoechi PZ, Okpala COR, Korzeniowska M. Bacterial contamination of Nigerian currency notes: a comparative analysis of different denominations recovered from local food vendors. PeerJ 2021;9:1-17.

[16] Jalali S, Kohli S, Latka C, Bhatia S, Vellarikal SK, Sivasubbu S, et al. Screening currency notes for microbial pathogens and antibiotic resistance genes using a shotgun metagenomic approach. PLoS One 2015;10(6):1-15. 
[17] Djoudi LN, Guezlane-Tebibel N, Mansouri K, Boumerdassi H, Arab K, Fardeau ML, et al. Multidrug-resistant opportunistic and pathogenic bacteria contaminate algerian banknotes currency. Pol J Microbiol 2020;69(4):491-501.

[18] Abd Alfadil NA, Suliman Mohamed M, Ali MM, El Nima EAI. Characterization of pathogenic bacteria isolated from sudanese banknotes and determination of their resistance profile. Int J Microbiol 2018;2018:Article ID 4375164.

[19] Lin J, Jiang W, Shi Y, Cai W. Metagenomic sequencing revealed the potential pathogenic threats of banknotes. ACS Omega 2021;6(5):3499-507.

[20] Sarwar A, Ahmad I, Amin A, Saleem MA. Paper currency harbours antibiotic-resistant coliform bacteria and integron integrase. J Appl Microbiol 2020;130(5):1721-9.

[21] Walsh PS, Metzger DA, Higushi R. Chelex 100 as a medium for simple extraction of DNA for PCR-based typing from forensic material. BioTechn 2013;54(3):134-9.

[22] Joon D, Nimesh M, Saluja D. Loop-mediated isothermal amplification as alternative to PCR for the diagnosis of extra-pulmonary tuberculosis. Int J Tuberc Lung Dis 2015;19(8):986-91.

[23] Nimesh M, Joon D, Varma-Basil M, Saluja D. Development and clinical evaluation of sdaA loop-mediated isothermal amplification assay for detection of Mycobacterium tuberculosis with an approach to prevent carryover contamination. J Clin Microbiol 2014;52(7):2662-4.

[24] Nimesh M, Joon D, Pathak AK, Saluja D. Comparative study of diagnostic accuracy of established PCR assays and in-house developed sdaA PCR method for detection of Mycobacterium tuberculosis in symptomatic patients with pulmonary tuberculosis. J Infect 2013;67(5):399-407.

[25] Notomi T, Okayama H, Masubuchi H, Yonekawa T, Watanabe K, Amino $\mathrm{N}$, et al. Loop-mediated isothermal amplification of DNA. Nucleic Acids Res 2000;28(12):e63.

[26] Pfyffer GE, Wittwer F. Incubation time of mycobacterial cultures: how long is long enough to issue a final negative report to the clinician? J Clin Microbiol 2012;50(12):4188-9.
[27] Gebert MJ, Delgado-Baquerizo M, Oliverio AM, Webster TM, Nichols LM, Honda JR, et al. Ecological analyses of mycobacteria in showerhead biofilms and their relevance to human health. bioRxiv 2018;9(5):1-15.

[28] Tomita N, Mori Y, Kanda H, Notomi T. Loop-mediated isothermal amplification (LAMP) of gene sequences and simple visual detection of products. Nat Protoc 2008;3(5):877-82.

[29] Notomi T, Mori Y, Tomita N, Kanda H. Loop-mediated isothermal amplification (LAMP): principle, features, and future prospects. J Microbiol 2015;53(1):1-5.

[30] Becherer L, Borst N, Bakheit M, Frischmann S, Zengerle R, von Stetten F. Loop-mediated isothermal amplification (LAMP)-review and classification of methods for sequence-specific detection. Anal Methods 2020;12(6):717-46.

[31] Martzy R, Kolm C, Krska R, Mach RL, Farnleitner AH, Reischer GH. Challenges and perspectives in the application of isothermal DNA amplification methods for food and water analysis. Anal Bioanal Chem 2019;411(9):1695-702.

[32] Kramer A, Assadian O. Survival of microorganisms on inanimate surfaces. In: Use of biocidal surfaces for reduction of healthcare acquired infections. Springer International Publishing, Cham, Switzerland, pp 7-26, 2014.

\section{How to cite this article:}

Nimesh M, Kang R, Joon D. Screening paper currency for Mycobacterium tuberculosis using loop-mediated isothermal amplification. J Appl Biol Biotech 2022; 10(01):221-225. 